\title{
Capsule Commentary on Ingebrigsten et al., Low Use and Adherence to Maintenance Medication in Chronic Obstructive Pulmonary Disease in the General Population
}

\author{
Theresa I. Shireman, PhD, RPh \\ J Gen Intern Med 30(1):96 \\ DOI: $10.1007 / \mathrm{s} 11606-014-3092-6$ \\ (c) Society of General Internal Medicine 2014
}

University of Kansas School of Medicine, Kansas City, KS, USA.

I ngebrigsten, et al. ${ }^{1}$ conducted a population-based study of patients with chronic obstructive pulmonary disease (COPD) in Denmark. Participants $(n=5,812)$ were stratified by COPD severity and maintenance respiratory medication use was examined for 1 year. Less than $10 \%$ of the cohort used any maintenance respiratory medications and even among patients with more severe COPD, use of respiratory medications was less than $40 \%$. Exacerbating this problem was that even among those prescribed medications, adherence was low.

These findings are not unique to suburban Copenhagen. A recent retrospective observational study of health insurance claims in the United States tracked patients after a COPD discharge and noted that only $56 \%$ filled a prescription for a long-acting bronchodilator in the 180 days post-hospitalization, with higher filling rates in the first 90 days as compared to days $91-180 .^{2}$

This investigation provides a valuable perspective on the prevalence and management of one of the leading causes of death and morbidity in the world. True population-based epidemiological investigations are expensive as they require detailed clinical measurements of a large number of persons, yet they are essential for appropriate public health surveillance. The overall prevalence rate $(\sim 10 \%)$ is consistent with other reports. What is perhaps most startling is the low concordance with international practice guidelines for maintenance respiratory medications. Evidence-based practice guidelines are meant to ensure the appropriate use of resources to achieve maximal health outcomes; adherence to global initiative for chronic obstructive lung disease (GOLD) guidelines for respiratory medications have been associated with lower health costs. ${ }^{3}$

Improvement will require direct patient engagement. A global patient study ${ }^{4}$ documented the mismatch between patients' perceptions of COPD and the impact of the disease on their lives. Their delays to treatment for exacerbations and perhaps overconfidence in their ability to manage their disease likely also underlie poor long-term adherence to maintenance medications. Physicians and other health care professionals also must be mindful of their roles in appropriate diagnosis, management, and monitoring of these patients. Together, we have many opportunities to reduce the burden of COPD, locally, nationally, and internationally, as Ingebrigsten and colleagues have aptly demonstrated.

Conflict of Interest: The author has no conflicts of interest with this manuscript.

Corresponding Author: Theresa I. Shireman, $\mathrm{PhD}, \mathrm{RPh}$; University of Kansas School of Medicine, 3901 Rainbow Blvd., MSN 1008, Kansas City, KS 66160, USA (e-mail: tshireman@kumc.edu).

\section{REFERENCES}

1. Ingebrigsten TS, Marott JL, Nordestgaard BG, Lange P, Hallas J, et al. Low use and adherence to maintenance medication in chronic obstructive pulmonary disease in the general population. $J$ Gen Intern Med. doi:10.1007/s11606-014-3029-0.

2. Baker CL, Zou KH, Su J. Long-acting bronchodilator use after hospitalization for COPD: an observational study of health insurance claims data. Int $\mathrm{J}$ COPD. 2014;9:431-439.

3. Asche CV, Leader S, Plauschinat C, Raparia W, Yan M, et al. Adherence to current guidelines for chronic obstructive pulmonary disease (COPD) among patients treated with combination of long-acting bronchodiloators or inhaled corticosteroids. Int J COPD. 2012;7:201-209.

4. Barnes N, Calverley PMA, Kaplan A, Rabe KF. Chronic obstructive pulmonary disease and exacerbations: patient insights from the global Hidden Depths of COPD survey. BMC Pulm Med. $2013 ; 13: 54$.

Published online November 11, 2014 